\section{The National Center for Advancing Translational Sciences' Intramural Training Program and Fellow Career Outcomes}

\author{
Brittany Haynes,* Kyle Brimacombe, Christy Hare, and Jessica Faupel-Badger \\ 'Division of Preclinical Innovation, National Center for Advancing Translational Sciences, Rockville, \\ MD 20850
}

\begin{abstract}
The National Center for Advancing Translational Sciences (NCATS) defines translational science as "the field of investigation focused on understanding the scientific and operational principles underlying each step of the translational process." A major goal of translational science is to determine commonalities across projects to identify principles for addressing persistent bottlenecks in this process. To meet this goal, translational scientists must be conversant in multiple disciplines, work in teams, and understand the larger translational science ecosystem. The development of these skills through translational science training opportunities, such as the translational science training offered by the NCATS intramural research program, prepares fellows for a variety of career options. The unique structure of the NCATS intramural program and the career outcomes of its alumni are described herein to demonstrate the distinct features of this training environment, the productivity of fellows during their time in training, and how this prepares fellows to be competitive for a variety of science careers. To date, the NCATS intramural research program has trained 213 people, ranging from high school to postdoctoral levels. These alumni have transitioned into a wide array of career functions, types, and sectors.
\end{abstract}

\section{INTRODUCTION}

Over the past decade, many organizations have turned their attention to the sustainability of the biomedical research workforce and particularly to the educational and professional development of graduate students and postdoctoral fellows entering these careers (Pickett et al., 2015). While this is not the first time individuals or organizations have drawn attention to the number of graduate students and postdoctoral fellows in the biomedical sciences and the career options available to them, these most recent efforts have resulted in a shift in how the community is approaching education and training. There are now more resources available for and broader acceptance of preparing graduate students and postdoctoral fellows for a wide array of career options, valuing all career choices, informing early-career scientists of how their skill sets are useful in these different settings, and being transparent about training outcomes to better inform fellows of career trends and options (Sinche, 2016; Blank et al., 2017; Evans et al., 2017).

Efforts by specific organizations have had a role in this shift, including the National Academies of Sciences, Engineering, and Medicine (NASEM) releasing a report titled Graduate STEM Education for the 21st Century and the National Institutes of Health (NIH) creating the Broadening Experiences in Scientific Training (BEST) awards (Meyers et al., 2016; NASEM, 2018). These initiatives share common themes, including the creation of institution-wide opportunities for early-career scientists to explore diverse career options and the development of skills important for all careers, such as communication (oral and writing) skills, project management, and working in a team
Erin L. Dolan, Monitoring Editor

Submitted Mar 13, 2020; Revised Jul 29, 2020; Accepted Jul 31, 2020

CBE Life Sci Educ December 1, 2020 19:ar51 DOI:10.1187/cbe.20-03-0048

*Address correspondence to: Brittany Haynes (Brittany.Haynes@anih.gov).

() 2020 B. Haynes et al. CBE-Life Sciences Education $\odot 2020$ The American Society for Cell Biology. This article is distributed by The American Society for Cell Biology under license from the author(s). It is available to the public under an Attribution-Noncommercial-Share Alike 3.0 Unported Creative Commons License (http://creativecommons.org/licenses/ by-nc-sa/3.0)

"ASCB®" and "The American Society for Cell Biology ${ }^{\circledR}$ " are registered trademarks of The American Society for Cell Biology. 
setting. The NASEM report also emphasized graduate science, technology, engineering, and mathematics (STEM) education that results in deep expertise in one STEM discipline while also developing "transdisciplinary literacy to suggest approaches to ... complex problems" (NASEM, 2018, p. 106). While some of these skills are easily acquired through traditional biomedical research training programs, others are not, potentially leaving fellows at a disadvantage in the broader workforce (Sinche et al., 2017).

There is remarkable consistency between the skills necessary to be successful in the emerging field of translational science (Gilliland et al., 2019) and the recommendations from the activities sponsored by the NASEM and NIH, making translational science training an opportunity to prepare fellows for multiple career options. Translational science is defined as understanding the scientific and operational principles underlying each step in the process of turning observations from the laboratory, clinic, or community into medical interventions (Austin, 2018). Beyond focusing on a single project, translational science involves determining commonalities across projects to identify principles that can be used to address bottlenecks in bringing advances from observation to public health practice and clinical implementation (Austin, 2018; Austin et al., 2019). Therefore, translational scientists must have broad training and be prepared to contribute to a translational science workforce crossing many career sectors.

The National Center for Advancing Translational Sciences (NCATS), part of the NIH, was established in 2011 to address a critical gap in bringing biomedical research advances to patients by defining this new field, establishing a research program, and developing a workforce focused on these larger issues in improving health (Collins, 2011). The stated mission of NCATS is to "catalyze the generation of innovative methods and technologies that will enhance the development, testing, and implementation of diagnostics and therapeutics across a wide range of human diseases and conditions" (Austin, 2018; Collins, 2011, p. 1). In addition to funding research at institutions across the country, NCATS has an intramural (i.e., on-site) research program within its Division of Preclinical Innovation (DPI) that is built around a multidisciplinary, team-based structure able to use a unique collection of expertise and technologies to address an array of complex translational research questions.

NCATS is also a founding member of an international collaboration of translational science organizations known as Translation Together (Gilliland et al., 2016). Translation Together members are collectively interested in raising awareness of translational science as a discipline and recently proposed a framework outlining the specific characteristics of a translational scientist. These attributes include being a boundary crosser, team player, process innovator, domain expert, rigorous researcher, skilled communicator, and systems thinker (Gilliland et al., 2019). DPI and others are adapting this framework from Translation Together, as well as the recent recommendations for graduate education and postdoctoral training, to shape their training programs for early-career scientists (Tsevat and Smyth, 2020). The organization of DPI combined with an intense focus on developing translational scientists provides a distinct type of training environment for early-career scientists and is an ideal site for testing and developing new approaches for implementing this framework. In this environment, fellows not only develop the crucial scientific skills offered by traditional biomedical research programs, but also the specialized skills required of a translational scientist (Table 1A).

Since 2011, DPI has steadily increased the number of positions in its translational science training programs, starting first with an emphasis on summer intern and postbaccalaureate fellow positions and more recently increasing postdoctoral positions (Figure 1). The increase in the number of training positions in DPI reflects both interest in DPI as a training opportunity and commitment from DPI leadership to expand the program. The team-based and multidisciplinary research within DPI has been a defining feature since its inception, and fellows at all levels benefit from this environment.

With efforts to define the characteristics of a translational scientist and provide career preparation, DPI fellows now have a more structured training program focused on instilling the characteristics of a translational scientist. As the science of translation is maturing, we sought to assess the career outcomes of DPI fellows from December 2011 (when DPI was established) through August 2019 (when data collection ended for this report). Here, productivity and career outcomes of DPI fellow alumni across education and career stages, from summer fellow to postdoctoral fellow, are reported. These data will be of interest to those involved in preparing early-career scientists for a variety of career options as well as fellows interested in translational science training. These data also form the initial base from which to evaluate future changes in the DPI training program, the framework of which may be of interest to those engaged in developing translational science training programs and traditional biomedical research training programs with a focus on career development.

\section{METHODS}

\section{NCATS Intramural Research Program-DPI}

NCATS DPI uses an approach wherein most projects are collaborations with outside entities, including investigators in other NIH Institutes and Centers, academic institutions, individuals in the private sector, and nonprofit organizations such as disease foundations and patient advocacy groups. For the fiscal year 2019, NCATS had 177 active internal projects funded by NIH, and new research collaborations are being established on a continuous basis (https://report.nih.gov). DPI expertise and technologies are applied to move these projects along the translational science pathway more quickly and hand projects off to the next partner on the path. In this environment, there is a greater turnover of projects; an outcome- or milestone-oriented mindset regarding what projects can best be advanced with DPI expertise and technology; and a focus on measuring the achievement of goals. This philosophy fits somewhere in between the traditional academic approach for biomedical research and research conducted within for-profit companies. True to NCATS' mission, the research projects in the intramural program often do not focus on a single disease or physiological system, but rather on a research question that could have broad implications across a number of diseases or conditions. There is also a special emphasis on riskier projects (e.g., limited data or new technologies) and those focused on rare and neglected diseases or health conditions with limited treatment options.

To foster the development of translational scientists, DPI provides short-term research experiences ( $~ 8-12$ weeks) to summer fellows at the high school, undergraduate, or graduate 
TABLE 1. Translational scientist characteristics and related DPI training components

A. The fundamental characteristics of a translational scientist as defined by Gilliland and colleagues (Gilliland et al., 2019) are a framework DPI is using to organize and expand the scientific and educational training components

Boundary crosser

Breaks down disciplinary silos and collaborates with others across research areas and professions to collectively advance the development of a medical intervention

Team player

Practices a team science approach by leveraging the strength and expertise and valuing the contributions of all players on the translational science team

Rigorous researcher

Conducts research at the highest levels of rigor and transparency, possesses strong statistical analysis skills, and designs research projects to maximize reproducibility

Process innovator

Seeks to better understand the scientific and operational principles underlying the translational process, and innovates to overcome bottlenecks and accelerate that process

Domain expert

Possesses deep disciplinary knowledge and expertise within one or more of the domains of the translational science spectrum ranging from basic to clinical to public health research and domains in between

Skilled communicator

Communicates with understanding with all stakeholders in the translational process across diverse social, cultural, economic, and scientific backgrounds, including patients and community members

Systems thinker

Evaluates the complex external forces, interactions, and relationships impacting the development of medical interventions, including patient needs and preferences, regulatory requirements, current standards of care, and market and business demands

B. Scientific and educational training components

\begin{tabular}{ll}
\hline Training program component & \multicolumn{1}{c}{ Related translational scientist characteristic } \\
$\begin{array}{l}\text { Research training } \\
\text { Working across multiple projects }\end{array}$ & $\begin{array}{c}\text { Boundary crosser, systems thinker, team player, process innovator, rigorous researcher, } \\
\text { skilled communicator } \\
\text { Rigorous researcher, domain expert, process innovator }\end{array}$ \\
$\begin{array}{l}\text { Evaluating robustness of assays } \\
\text { Learning Assay Guidance Manual principles }\end{array}$ & $\begin{array}{l}\text { Rigorous researcher, domain expert, process innovator } \\
\text { Communicating with internal and external collaborators }\end{array}$ \\
$\begin{array}{l}\text { Skilled communicator, team player, boundary crosser } \\
\text { Educational and professional development activities }\end{array}$ & Boundary crosser, systems thinker, team player, process innovator \\
Case studies & $\begin{array}{l}\text { Skilled communicator, boundary crosser, domain expert } \\
\text { Monthly fellows' meeting } \\
\text { Group meeting presentations }\end{array}$ \\
Annual poster day & Skilled communicator, boundary crosser, domain expert \\
Invited speaker seminars & Skilled communicator, boundary crosser, systems thinker \\
\hline
\end{tabular}

level, 1- to 2-year postbaccalaureate positions, and postdoctoral training positions (maximum of 5 years), and participates in the NIH Graduate Partnerships Program for predoctoral (PhD) students. DPI research teams are organized around the following programs (Figure 2): Early Translational Branch (formerly NCATS Chemical Genomics Center), which includes 3D Tissue Biofabrication; Therapeutic Development Branch; Chemical Genomics Branch, which includes Assay Development and Screening Technologies, Chemistry Technologies, Functional Genomics Laboratory, Stem Cell Translation Laboratory, and Toxicology in the $21^{\text {st }}$ Century; and Core Facilities, including Informatics, Analytical Chemistry, and Research Services.

\section{Training Program Components}

Before the establishment of an official training office in 2018, the DPI team leads and mentors created training initiatives with a focus on summer and postbaccalaureate fellows, as these populations represented the vast majority of fellows and providing them research experiences is essential for them to develop an identity as scientists (Lopatto, 2007; Russell et al., 2007; Remich et al., 2016; Hernandez et al., 2018). The DPI training office built upon the initiatives already in place to further instill in fellows the skills needed for translational science. Additionally, initiatives were expanded to formalize postdoctoral training. The training offered within the DPI research program can be divided into research training and additional education and professional development activities (Table 1B).

\section{Research Training}

DPI focuses on creating a scientifically rigorous multidisciplinary environment for fellows. This is exemplified by DPI's leadership on training using the Assay Guidance Manual (Coussens et al., 2018). The Assay Guidance Manual originated in a collaborative effort with Eli Lilly. DPI staff have greatly expanded this manual and serve as lead organizers and lecturers in the Assay Guidance Manual workshops, both nationally and internationally. As such, DPI staff serve as exemplars of scientific robustness and rigor to DPI fellows and expose fellows 
Fellowship Positions by Year

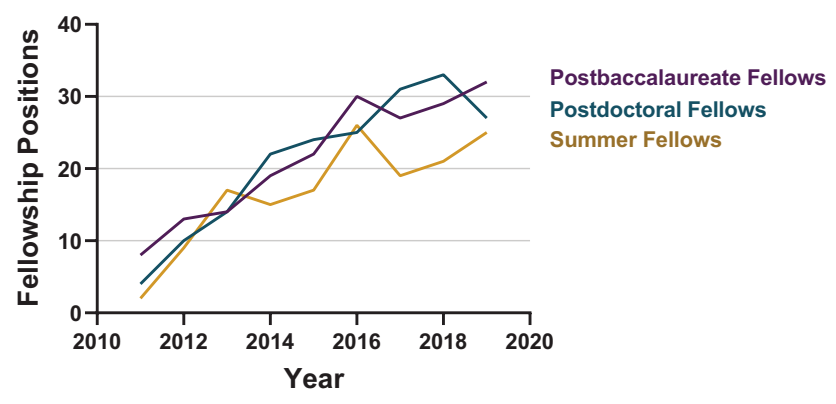

FIGURE 1. NCATS/DPI intramural training program growth. The NCATS translational science training program has experienced steady growth since being established in 2011. The training office was officially established in $\mathbf{2 0 1 8}$ to accommodate the increase in the number of fellow positions available. The line graph shows the number of occupied fellowship positions for each given year. Numbers include alumni $(n=213)$ and current fellows $(n=49)$ as of August 2019. Note: summer fellowship positions are currently capped at 25.

to the principles described in the Assay Guidance Manual, such as consistent use of orthogonal assays to rule out false positives from high-throughput screens. Further, fellows are encouraged to utilize the Assay Guidance Manual when developing projects and assays to ensure rigor and reproducibility.
DPI fellows also have access to state-of-the-art instrumentation and informatics tools in this scientifically rigorous environment. A great strength of the DPI training program is the cross-disciplinary interactions. As shown in Figure 2, multiple research groups use similar technologies and skills to complete their projects, resulting in substantial collaboration among disciplines. In this environment, fellows learn multiple skills from domain experts and gain additional scientific and career mentorship. Further, fellows are involved in group meetings outside their fields of expertise. These interactions allow for fellows to engage in multiple collaborative projects and to observe how scientists from different disciplines evaluate assay robustness through troubleshooting and problem solving, and how they approach problems in preclinical research (Table 1B). To manage these projects, DPI fellows routinely use electronic notebooks, similar to those used in biotechnology and pharmaceutical companies. These initiatives set the framework for developing translational scientists with the ability to communicate across scientific disciplines, work collaboratively on teams, and produce scientifically sound data.

\section{Education and Professional Development Activities}

Individuals who enter DPI in training positions are new to both the field of translational science and the team-based structure of DPI. Therefore, the case study approach has been adopted for teaching preclinical translational science principles to our intramural fellows. This approach of walking through a real example

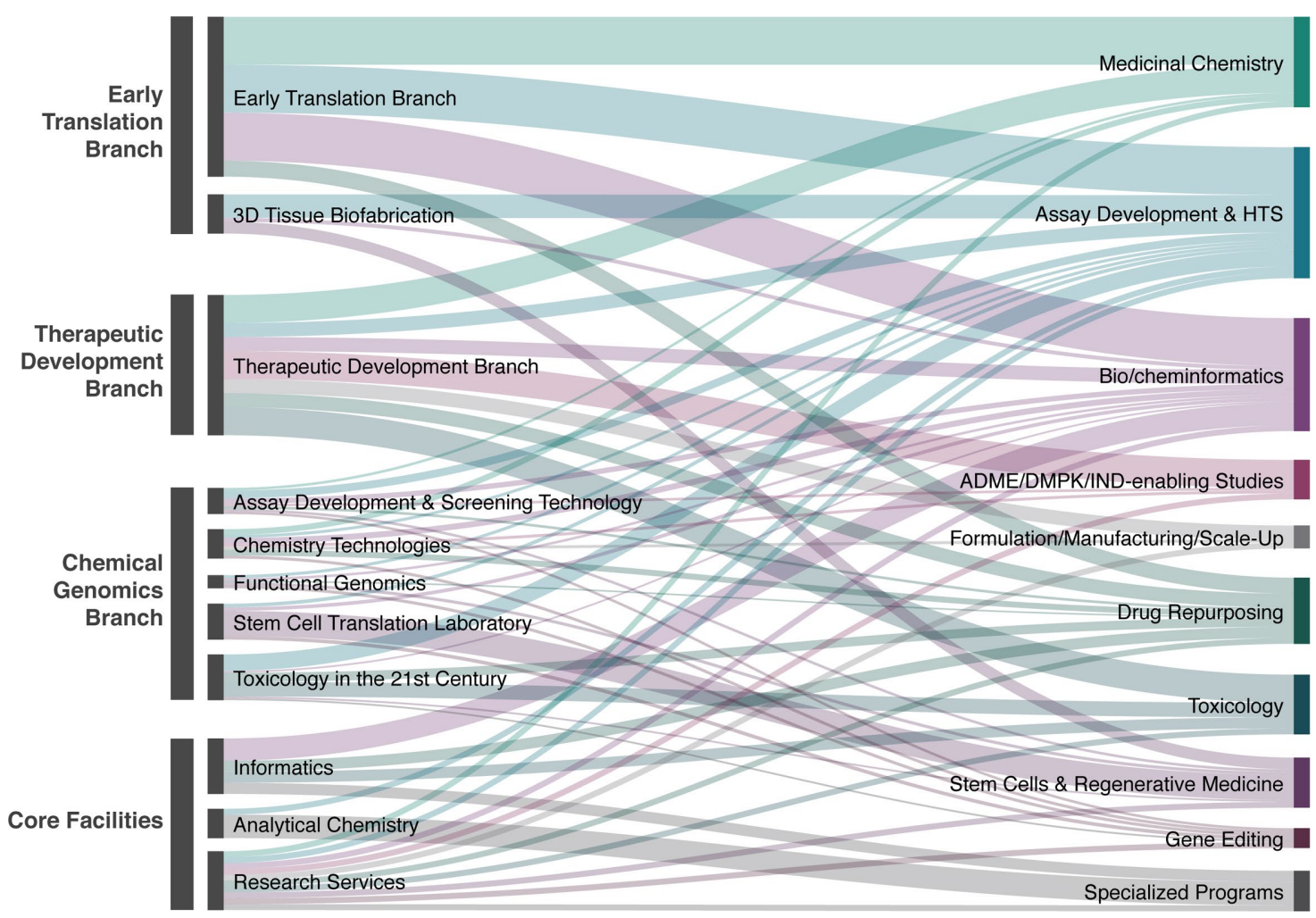

FIGURE 2. Organizational and collaborative structure of DPI. DPI research teams (left) are organized into specific branches and use a variety of technologies and skill sets (right) to complete research projects. The overlap and complementarity of the expertise in DPI creates a collaborative environment in which fellows can interact with domain experts, learn to communicate and work across scientific disciplines, and learn to manage multiple projects. 
to show how theoretical concepts can be applied is used in a variety of different settings, including in business and law, to further engage students and enhance their understanding of the many facets of an issue, and by the National Mentoring Research Network to introduce scientists to mentoring skills, research identity, and practical research skills (Sorkness et al., 2017). In the biological sciences, case studies have been positively correlated with learning gains in oral and written communication skills (Bonney, 2015; Bi et al., 2019). Case studies of projects with substantial involvement of NCATS scientists are now being used to illuminate the preclinical translational science process and further highlight the characteristics of a translational scientist as described by Gilliland and colleagues (2019). These integrated case studies are composed of five to six different sessions, each approximately 1.5 hours in length. Most of the presenters are scientists from DPI who discuss the origin, conceptualization, management, and outcomes of preclinical translation projects from target validation through probe/lead/clinical candidate development to filing an Investigational New Drug application with the Food and Drug Administration (FDA), in order to convey the scientific and operational innovations and knowledge, skills, and behaviors that allowed the project team to achieve their goals. In each session, there are multiple presenters, so the contributions of the different disciplines can be seen across each presentation, along with the transition points between groups and where collective decisions were needed. The lectures interweave the threads of the story and are presented in a way that the fellows can see how different facets of the project were being tackled at the same time. These case studies are open to all fellows from postbaccalaureate to postdoctoral levels. While the case studies follow individual projects, they are used to illustrate common issues in translational science. This allows fellows to reflect on these concepts and how they apply to their current work, giving them the opportunity to think about the system-wide issues in translational science and innovations they can make to improve the translational process. Indeed, fellows at all stages have indicated these case studies have helped them develop a greater appreciation of the translational science process and a broader view of the diverse expertise needed. These case studies are now being adapted for an online course that will be offered annually through the Foundation for Advanced Education in the Sciences at the NIH (www.faes.org; course number: MEDI501; course description in the Supplemental Material). Distributing this course more broadly allows it to serve as a resource for those developing and enhancing their translational science training programs and address an immediate challenge in the emerging field of translational science (Tsevat and Smyth, 2020).

The DPI training office also facilitates monthly fellows' meetings and annual poster days to give fellows ample opportunity to present their research and sharpen their communication skills. Additionally, outside speakers from industry, academia, and government are invited to interact with fellows (Table 1B). During these sessions, fellows learn about the science being conducted by the speaker and gain insight into different scientific career paths available to them as potential translational scientists. Finally, the development of individual development plans (IDPs) by all postbaccalaureate, predoctoral, and postdoctoral fellows and the development of men- tee-mentor agreements by summer fellows provides fellows the opportunity to consider their professional development and discuss this with their team leads and mentors. IDPs can be an effective career development tool that promotes positive mentoring relationships, a necessity for early-career scientists (Vanderford et al., 2018a,b; Weggemans et al., 2018). Implementation of this resource ties together the translational science training with the ability for fellows to map where their training will take them by providing the opportunity to begin thinking of and preparing for various career options.

\section{Alumni Classification}

For this study, the career trajectories of summer fellows, postbaccalaureate fellows, predoctoral fellows, and postdoctoral fellows were examined. DPI has trained an array of alumni, from summer fellows through postdoctoral fellows. Some fellows have come to DPI for a summer and returned as postbaccalaureate fellows or started as a postbaccalaureate fellow and returned as a postdoctoral fellow. To account for these changes in fellowship positions, and to capture the total numbers for each fellow population, fellows who served at DPI under multiple fellowship positions were included in all fellowship position categories into which they fell (e.g., an individual who was initially a summer fellow and who later joined as a postbaccalaureate fellow is counted twice: once as a summer fellow and once as a postbaccalaureate fellow; however, they are counted only once when the total NCATS alumni cohort is described).

As DPI is a collaborative research environment, fellows have the opportunity to work across multiple research groups and projects. To account for this and take into consideration the impact of training across groups, alumni who conducted fulltime research in more than one research group were included in both groups. Importantly, those fellows who returned to the same research group in different fellowship positions were only counted once in that research group. Using this approach, alumni fellow data demonstrate that fellows have been actively involved in the Early Translational Branch $(n=70)$, Therapeutic Development Branch $(n=38)$, Toxicology in the $21^{\text {st }}$ Century ( $n=25)$, Research Services Core $(n=23)$, Assay Development and Screening Technology $(n=27)$, Functional Genomics Laboratory $(n=14)$, Informatics Core $(n=15)$, Chemistry Technologies $(n=10)$, Analytical Chemistry Core $(n=2)$, and 3D Tissue Biofabrication $(n=3)$.

To avoid overestimating the diversity and impact of the DPI training program, returning fellows (i.e., a fellow who started as a summer fellow and returned as a postbaccalaureate fellow) were only counted once for demographic data and career outcome data, regardless of whether they returned to different groups or returned under a different fellowship position. For career outcomes, a fellow was included in counts associated with the final fellowship position at DPI (i.e., a fellow who trained as a summer fellow and returned as a postbaccalaureate fellow was counted only as a postbaccalaureate fellow for career outcomes).

Finally, fellows who returned to DPI, whether in a different research group or under a different fellowship position but were still in a training position as of August 2019 (e.g., a fellow who started as a summer fellow and is currently a postbaccalaureate fellow) were not included as alumni. As of August 2019, there were 49 fellows in DPI in the Early Translational Branch 
$(n=12)$, Therapeutic Development Branch $(n=14)$, Toxicology in the $21^{\text {st }}$ Century $(n=4)$, Assay Development and Screening Technologies $(n=7)$, Informatics Core $(n=4)$, Chemistry Technologies $(n=2)$, Analytical Chemistry Core $(n=2)$, 3D Tissue Biofabrication $(n=2)$, and Stem Cell Translation Laboratory $(n=2)$.

\section{Data Collection}

Data collection for fellow alumni occurred in three phases:

Phase 1 consisted of collaborating with team leads and mentors to gather informal records on fellow alumni names, current job titles, and current job sectors. Fortunately, team leads and mentors maintained thorough records $(n=122)$ of their fellows and provided an excellent base upon which to build.

Phase 2 involved surveying administrative staff and official administrative records to verify the informal team lead and mentor records. Additionally, these official records were used to obtain the start and end dates of fellows, determine a fellow's fellowship position (i.e., summer fellow, postbaccalaureate, predoctoral, or postdoctoral fellow, or volunteer), and obtain demographic data.

Phase 3 used online databases (i.e., university/company directories, LinkedIn, and Google) to verify alumni current job titles and sectors and collect email addresses. Well-maintained profiles served as a record of career trajectory showing each transition of fellow alumni from the time they completed their training in DPI to their current career positions. An internal DPI publications site was used to determine the number of publications to which fellow alumni contributed. PubMed was also used to verify these data and identify additional fellow publications. Manuscripts that were published while the fellow was affiliated with DPI were included in the publication counts. To account for manuscripts that may have been published after the fellow transitioned from DPI, publications including the alumni and two or more DPI scientists were also included. Additionally, staff from the DPI Office of Strategic Alliance provided patent and invention records for fellow alumni.

\section{Career Outcomes Taxonomy}

To remain consistent with emerging literature, the unified taxonomy of biomedical $\mathrm{PhD}$ career trajectories developed by representatives from the Association of American Universities, the Association of American Medical Colleges, the NIH BEST consortium, and other universities and organizations was used (Mathur et al., 2018a; Pickett and Tilghman, 2018). This taxonomy is a three-tier description of career paths. The first tier is the broadest and covers the career sector (i.e., academia, government, for-profit, nonprofit, and other). Career type is the second tier and represents a coarse description of job duties and activities (i.e., primarily research, science related, primarily teaching, non-science related, and further training or education). The third and final tier focuses on job functions and serves as a specific descriptor of the job alumni hold. This taxonomy has been used for reporting postdoctoral career outcomes. For this report, the taxonomy is being adapted for all fellow positions at DPI, including summer fellows and postbac- calaureate and predoctoral fellows. Therefore, fellows completing their undergraduate or graduate degrees were not included in the third taxonomy tier. The "completing further education and training" descriptor in the third taxonomy tier was reserved for those fellows completing clinical residency programs only; postbaccalaureate and predoctoral fellows were excluded.

\section{Aggregate Data Reporting}

All data are reported in aggregate with identifiable information removed to maintain confidentiality and anonymity of the individuals.

\section{RESULTS \\ DPI Fellows Represent Diverse Populations}

Due to the breadth of research disciplines within DPI, the training and education program attracts a broad range of fellows from high school students to postdoctoral fellows. These fellows work with DPI through different fellowship positions (Figure 3A) and participate in training activities specific to their experience levels to foster their development as translational scientists. Since the start of DPI in 2011, DPI has trained 213 fellows (12 of whom returned to DPI under different fellowship positions). Nearly half of the fellow alumni were hired as summer fellows (51\%) through the NIH Summer Internship Program. While these fellows account for a large portion of the alumni population, these are only short-term research experiences of 8-12 weeks. Among the more stable fellow populations at DPI, those who are here for a minimum of 1 year, postbaccalaureate fellows account for $27 \%$ and postdoctoral fellows account for $19 \%$, with a small fraction of predoctoral (graduate partnership program) students (3\%). Cumulatively, $81 \%$ of the DPI alumni population consists of undergraduate, postbaccalaureate, or predoctoral fellows. This larger percentage reflects that the training program started with an emphasis on this population of fellows early in their education and training and they readily benefited from both research experience and career development aspects (Lopatto, 2007; Russell et al., 2007; Remich et al., 2016; Hernandez et al., 2018).

The gender distribution of the alumni population is $59 \%$ male and 41\% female. (Figure 3B). Citizenship was another factor used to measure our fellow diversity. In accordance with the NIH policy, postdoctoral fellows can be U.S. citizens, permanent residents, or foreign nationals, while the other fellowship positions are largely limited to U.S. citizens and permanent residents. International fellows account for $40 \%$ of postdoctoral fellows (Figure 3C). When all alumni fellow populations were included in this measure, the overall international alumni fellow population is $9 \%$ (unpublished data). Race and ethnicity are collected on a voluntary basis; therefore, these metrics were not captured for more than $90 \%$ of alumni and were not included in the report.

\section{Fellow Productivity}

Publications, patent applications, and invention records of fellow alumni were used as a measure of productivity (Table 2). These metrics were chosen because translational science skills such as being a skilled communicator across disciplines and professions, a domain expert, and a rigorous researcher are essential for producing publications, patent applications, and inventions. For predoctoral alumni, due to small numbers, these 
A Fellow Alumni Positions

$(n=225)^{*}$

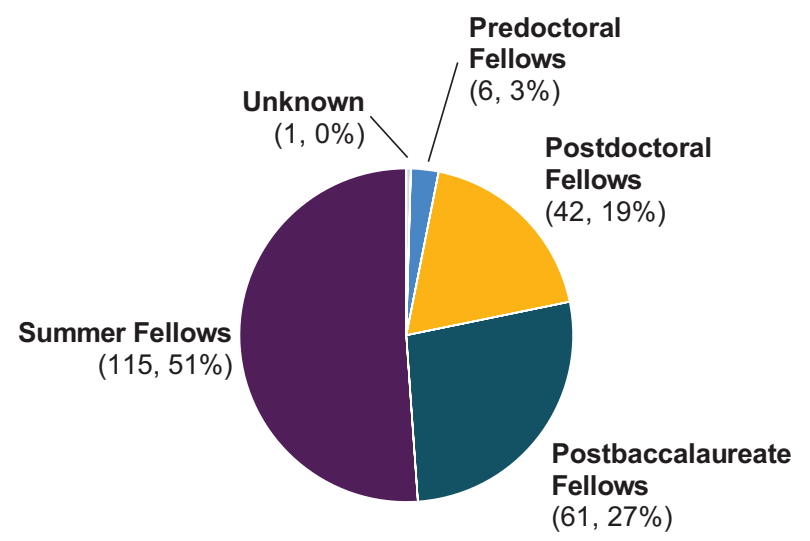

B
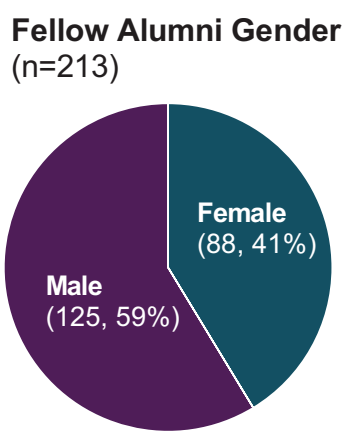

C

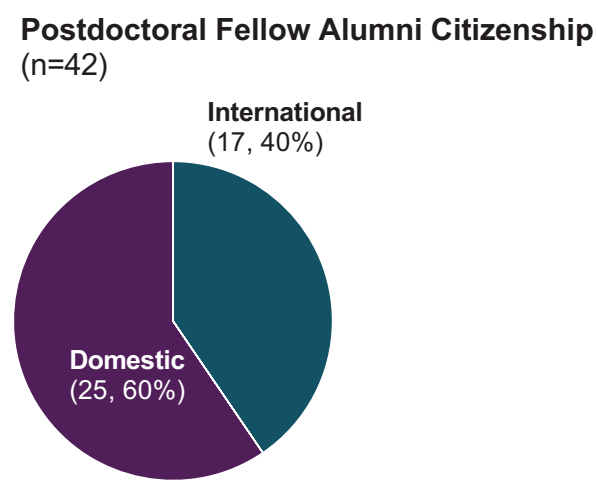

FIGURE 3. DPI fellow alumni demographics. Fellow alumni span the breadth of fellowship positions (A) and are nearly evenly distributed among males and females (B). Due to NIH policy, international fellows (C) are limited to only the postdoctoral appointment and account for $40 \%$ of this population at DPI. *Includes fellows $(n=12)$ who returned in multiple fellowship positions.

metrics were consolidated with those of postdoctoral alumni to maintain anonymity. Alumni publication records were mined manually using an internal DPI publications database and PubMed, querying the name of each individual and examining the authors' information and the submission and publication dates. To account for manuscripts developed while the fellow was affiliated with DPI but that may have been published after the fellow transitioned from DPI, publications including the alumni with two or more DPI scientists as contributing authors were also included. Among the postbaccalaureate and predoctoral/postdoctoral alumni, more than half published while affiliated with DPI (66\% and 63\%, respectively). Additionally, 8\% of the summer alumni published through their affiliation with DPI. Of the postbaccalaureate and postdoctoral alumni, $3 \%$ and $10 \%$, respectively, were listed on patent applications and collaborated with the DPI Office of Strategic Alliances to complete these filings. Overall, DPI fellow alumni have contributed to 235 publications, 11 patent applications, and 11 inventions over a span of approximately 8 years, from the inception of DPI in December 2011 through August 2019, when data collection ended for this report. The value of these metrics is further strengthened given that the average time postbaccalaureate and postdoctoral fellows spend at DPI is 1.5 years and 2.5 years, respectively. These data may also be underestimates, as 33\% of fellow alumni included here (72 total alumni, 41 summer fellows, 21 postbaccalaureate fellows, 1 predoctoral fellow, and 9 postdoctoral fellow) left DPI between January 2018 and August 2019 and are likely to have had manuscripts, patent applications, and inventions that were in various stages of preparation and submission there were not included in the totals here, because only published, publicly available materials through August 2019 were counted for these productivity measures. In addition, manuscripts with fewer than two DPI scientists as coauthors that were published after a fellow left DPI were not included.

\section{Career Outcomes of Fellow Alumni}

The overall goal of the DPI training program is to train translational scientists. In doing so, DPI is also developing fellows who are prepared for a broad array of scientific careers. To examine the career outcomes of fellow alumni, the unified taxonomy of biomedical $\mathrm{PhD}$ career trajectories was adapted for all fellow positions at DPI (Mathur et al., 2018a; Pickett and Tilghman, 2018). Therefore, fellows completing their undergraduate or graduate degrees were not included in the third taxonomy, as no job function category is available to properly code these 
TABLE 2. Productivity of DPI fellow alumni while affiliated with DPI ${ }^{a}$

\begin{tabular}{lcrc}
\hline & $\begin{array}{c}\text { Summer alumni } \\
(\boldsymbol{n}=\mathbf{1 1 5})\end{array}$ & $\begin{array}{c}\text { Postbaccalaureate alumni } \\
(\boldsymbol{n}=\mathbf{6 1})\end{array}$ & $\begin{array}{c}\text { Postdoctoral alumni } \\
(\boldsymbol{n}=\mathbf{4 8})^{\mathrm{b}}\end{array}$ \\
\hline Number of publications & 11 & 104 & 120 \\
\% of alumni with publications & 8 & 66 & 63 \\
Number of patent applications $^{\mathrm{c}}$ & 0 & 4 & 7 \\
\% alumni with patent applications & & 3 & 7 \\
Number of inventions & 0 & 4 & 10 \\
\% alumni with inventions & 0 & 3 & 10 \\
Average length of traineeship & 10 weeks & 1.5 years & 2.5 years \\
\hline
\end{tabular}

apublications, patent applications, and invention records of fellow alumni were used as a measure of productivity. Alumni at all levels have published while affiliated with NCATS, with more than half of the postbaccalaureate and postdoctoral alumni publishing during their 1.5-2.5 years at NCATS. Overall, DPI trainee alumni have contributed 235 publications, 11 patent applications, and 11 inventions.

bIncludes postdoctoral and predoctoral fellow alumni to maintain anonymity.

'Referencing patent applications filed in the United States.

alumni. More than half of the DPI alumni are in academia, defined as any postsecondary academic institution where training occurs (62\%; Figure 4A). This is not surprising, given that the two largest alumni populations are summer fellows and postbaccalaureate fellows (Figure 3A). Examining these populations, $70 \%$ of summer fellow alumni and $75 \%$ of postbaccalaureate fellow alumni are in academia (Figure 4, B and D). Of those summer fellow alumni in academia, 95\% are furthering their education, with a vast majority (73\%) pursuing an undergraduate degree (Figure 4C). Similarly, 93\% of postbaccalaureate fellow alumni in academia are furthering their education, with $63 \%$ obtaining a $\mathrm{PhD}$ or $\mathrm{MD} / \mathrm{PhD}$ and $23 \%$ pursuing an MD (Figure 4E).

When looking at only the alumni postdoctoral fellow population (Figure 4F), nearly half of this population (43\%) work for a government agency, such as the FDA or institutes and centers within the NIH. The remaining postdoctoral alumni work at forprofit companies (24\%), in academia (21\%), or with nonprofit (10\%) organizations. Across all fellow alumni, 55\% are furthering training and education, again owing to the large proportion of summer fellow and postbaccalaureate alumni, and $31 \%$ are in jobs that are science focused (i.e., science related and primarily research; Figure 4G). With the removal of those furthering training and education, $71 \%$ of alumni are in science-focused career types (unpublished data). Of alumni not currently in further training or education positions (i.e., high school, undergraduate, graduate, and professional school students), their job functions span the breadth of the translational science spectrum (Figure $4 \mathrm{H}$ ), a testament to the DPI translational science training program preparing alumni to be competitive for multiple scientific career sectors. Here, the "completing further training" descriptor refers to those alumni in clinical residency programs. Importantly, while DPI alumni have job functions outside academia or bench science, most of the alumni (71\%) not categorized as "furthering training or education" still engage in science-related jobs and jobs primarily in research.

\section{DISCUSSION}

The call for a more student-centered and skills-based approach to training future scientists has been issued by NASEM and the $\mathrm{NIH}$, among others, in reports and articles written about graduate education and training in the biomedical sciences (Pickett et al., 2015; Meyers et al., 2016; Her et al., 2018; NASEM, 2018; Zimmerman, 2018). In addition, data from the 2017
National Science Foundation (NSF) Survey of Doctorate Recipients demonstrated that, for the first time in survey history, almost as many life and health sciences PhD's were employed in the private sector $(42 \%)$ as in academia (43\%), indicating a critical need for training approaches that emphasize preparedness for a broad array of career options (NSF, 2017). As fellows continue to be interested in a broad array of career options and seek out relevant training, it is essential that training programs focus on preparing fellows for multiple career options, including academia. The newly emerging field of translational science requires individuals to be able to communicate and work collaboratively across scientific disciplines and professions, in addition to being competent researchers in their scientific disciplines, in order to successfully traverse each step of the translational process. In this report, we provide data from the DPI translational science training program to show that the collective translational scientist skill set also prepares scientists for a variety of science careers.

As of August 2019, DPI has trained 213 translational scientists from high school to postdoctoral levels. This report details alumni fellow demographics, scientific productivity, and career outcomes. Current data on career outcomes presented here show the DPI training program is preparing alumni to be competitive for multiple career sectors, career types, and career functions. Across all DPI alumni no longer in training, $71 \%$ are in science-related jobs or jobs primarily in research with job functions across the scientific spectrum (unpublished data). Similar results were reported by the Translational Science Training Program offered by the NIH Office of Intramural Training and Education in collaboration with DPI, in which $75.7 \%$ of participants at the postdoctoral and predoctoral levels transitioned to positions outside academia (Gilliland et al., 2017). This indicates that a variety of translational science training experiences can increase awareness of and prepare individuals for a range of career options across the biomedical ecosystem.

This study describes the outcome of translational science training designed to prepare fellows for a variety of career options. However, there are limitations in this study. One of these limitations arises from the methods by which the data were collected. Data were collected using internal administrative records and publicly available information. Unfortunately, this data-collection method does not take the alumni perspective into account regarding demographic data, career outcomes, and the impact of their translational science training on their 
A

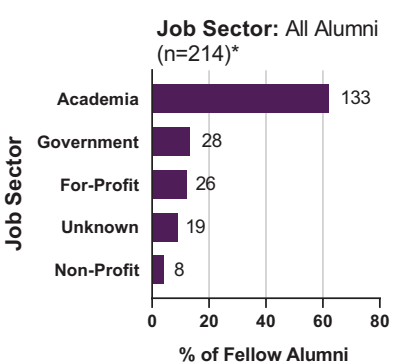

D

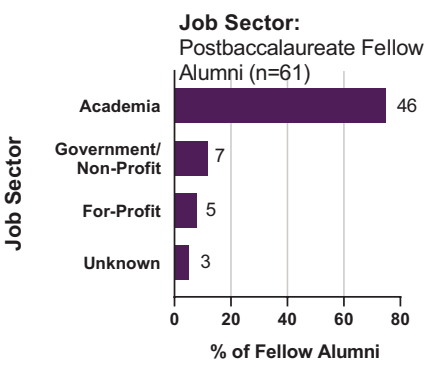

G

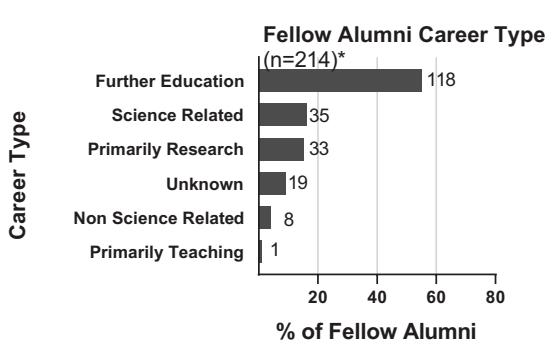

B

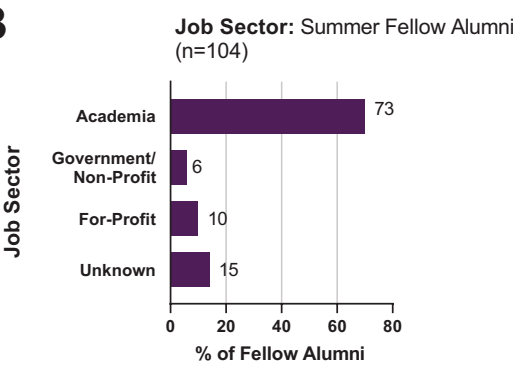

$\mathbf{E}$

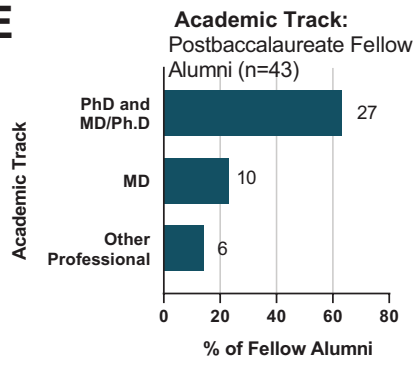

C Academic Track: Summer Fellow Alumni $(n=69)$

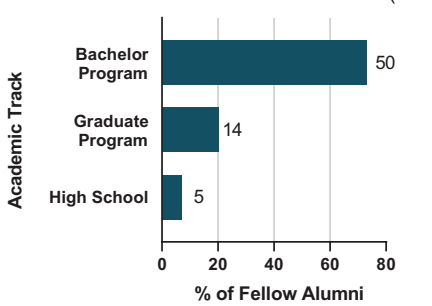

$\mathbf{F}$

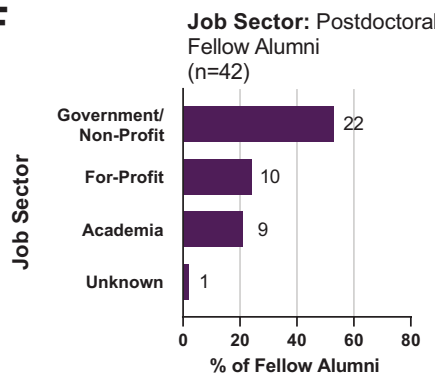

Fellow Alumni Job Function

H

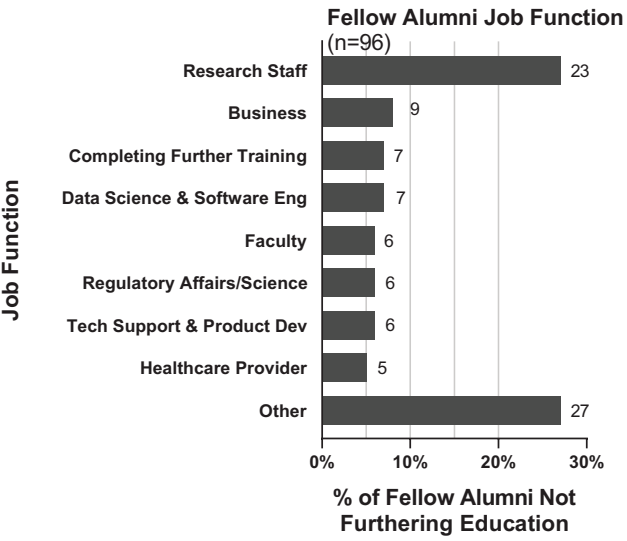

FIGURE 4. DPI fellow career outcomes. Most fellow alumni are still in academic positions (A). The vast majority of these alumni are summer and postbaccalaureate fellows still pursuing further education (B-E). Note, multiple degrees are included in some categories, as follows: graduate programs: $\mathrm{PhD}, \mathrm{MD}, \mathrm{MD} / \mathrm{PhD}, \mathrm{MS}, \mathrm{MBA}$; bachelor's programs: BS, BA; other professional: DDS, MS, PA. Among postdoctoral alumni (F), a majority are in government. However, alumni trainees in "science-related" or "primarily research" career types (G) still account for $31 \%$ of all alumni and $71 \%$ of alumni not pursuing further training and education (unpublished data). Of those alumni not pursuing further education, their job functions span the breadth of the translational science pathway (H). Note: the "completing further training" descriptor refers to those alumni in residency programs. Also, multiple job functions are included some categories as follows: research staff: research staff, senior scientist, and group leaders; health care provider: health care provider and clinical services; business: business development, sales and marketing, and entrepreneurship.*An individual works in two job sectors.

career trajectories. While standard protocols were used to gather and classify demographic data and career outcomes, these data rely solely on the interpretation of the job title by the coders, which may differ from how an individual would classify their career data (Stayart et al., 2020). To address this concern in future studies, an alumni survey is being developed to allow self-reporting of demographic data and career outcomes. The use of a standard survey for self-reported career outcomes may overcome the inconsistencies associated with third-party career outcome coding (Stayart et al., 2020). Another limitation of this study is the potential selection bias that occurs due to the nature of the DPI training program. Fellows attracted to this opportunity may already have an interest in careers outside the traditional academic research environment, resulting in more alumni with careers outside academia. Entrance and exit surveys are being developed to assess the career goals of fellows joining DPI and the impact of the training program on these goals. These surveys will allow for the reporting of the percentage of alumni who entered DPI intending to work outside the traditional academic research environment and will provide context to the percentage of alumni working outside academia in future reports.

When examining the postdoctoral alumni of the DPI training program, most work in the government or nonprofit (52\%) and for-profit (23\%) sectors, with $21 \%$ transitioning into academia (Figure 4F). In contrast, analyses of fellows at Wayne State University and the University of California-San Francisco reported that most of their postdoctoral alumni $(58 \%$ and 
54.4\%, respectively) remained in academia (Silva et al., 2016; Mathur et al., 2018b). DPI results are also in contrast with a publication from the National Institute of Environmental Health Sciences in which $49 \%$ of the postdoctoral alumni go on to academia and only 15\% work in government (Xu et al., 2018). These data indicate that the skills, mentorship, and experiences acquired from translational science training may increase awareness of and better prepare fellows for a variety of careers outside academia.

The DPI training program offers fellows a variety of opportunities to prepare for scientific careers that may not be found in traditional academic training programs. A recent publication evaluating PhD training in the biomedical sciences concluded that many skills obtained during graduate school, such as discipline-specific knowledge, oral and written communication skills, and the ability to manage a project, are valuable for both research-intensive and non-research intensive career paths (Sinche et al., 2017). However, it was also concluded that graduate students did not readily attain other skills, such as the ability to set a vision and determine goals, work on a team, and collaborate outside the organization (Sinche et al., 2017). Due to the structure of the DPI training program, working in teams and collaborating outside the organization are skills all fellows must acquire. Additionally, the collaborations in which DPI fellows participate consistently involve individuals from a variety of scientific disciplines and other professions. The ability of DPI alumni to effectively obtain these skills is made evident by the 235 publications, 11 patent applications, and 11 inventions they have produced. These metrics indicate that fellows interact with many contributing authors from across scientific disciplines and with technology transfer offices on projects with the goal of advancing impactful research projects along the translational science spectrum.

Sinche and colleagues (2017) found that career planning and awareness skills ranked the lowest of all skills acquired by science PhDs. A paper by St Clair and coauthors (2017), examining the career preparedness of doctoral fellows, found that how the fellows perceived the support they received in career exploration from their institutes had a strong direct impact on their career planning. A recent publication detailing the impact of the BEST awards found a high level of awareness amongst BEST fellows regarding career options (Lenzi et al., 2020). As these awards suggest to fellows a commitment by their institutions to promote career exploration, the observed increased level of career awareness may be a result of this support. The team science nature of the DPI training program explicitly introduces fellows to a variety of career options and thus demonstrates institutional support in career exploration. The DPI training office also makes a conscious effort to provide fellows with ample opportunity for career exploration. Of note, invited speakers from different translational science career paths give career seminars to broaden the career awareness of DPI fellows.

Work published by Gibbs and colleagues (2015) examining the career development of postdoctoral fellows found that only $26 \%$ of postdocs had knowledge regarding career options for $\mathrm{PhDs}$ and recommended career development over the full course of scientific training. The National Institute of General Medical Sciences at NIH has funded many institutions to develop postbaccalaureate fellows academically and profes- sionally through the Postbaccalaureate Research Education Program (PREP) with the goal of offering fellows career development at this early stage (Hall et al., 2015, 2016). An analysis of overall fellow outcomes from PREP reveals that, while a majority of fellows matriculate into $\mathrm{PhD}$ programs, fellows also enter $\mathrm{MD} / \mathrm{PhD}$, and PharmD programs, as well as various professional degree programs (i.e., MD, DO, DDS, etc.), master's programs (i.e., MS, MPH, etc.), and bachelor's programs (i.e., BA, $\mathrm{BS}$, etc.). Consistent with these efforts to provide career development at earlier career stages, $81 \%$ of all DPI alumni are undergraduate, postbaccalaureate, or predoctoral fellows and are being exposed to multiple career paths. Comparable to the overall PREP outcomes, DPI postbaccalaureate fellow alumni matriculate into a broader array of academic tracks (PhD: $56 \%$; MD: 2\%; MD/PhD: 7\%; DDS: 7\%; MS: 5\%; PA: 2\%). The ability of DPI to offer these valuable professional skills and career development to all levels of fellows prepares fellows for success in a variety of careers. Notably, Sinche and coauthors (2017) commented that these skills_-career planning and awareness and the ability to work with others outside the organizationwere favorably associated with research-intensive careers, supporting the assertion that the DPI training program is preparing fellows for broad career options within science.

The career outcomes of DPI alumni are a testament to the value of translational science training and the value of the DPI training program more specifically. Training translational scientists requires fostering the development of multiple key characteristics, including but not limited to the ability to cross disciplinary boundaries, work in multidisciplinary and multiprofessional teams, communicate across disciplines and professions, and develop projects that meet the needs and requirements for advancing interventions along the translational pathway. The acquisition of these skills, recognized as the fundamental characteristics of translational scientists (Gilliland et al., 2019), requires specific training. The DPI training program focuses on developing translational scientists with these skills by creating a scientifically rigorous multidisciplinary environment (Table 1). Within this environment, fellows work in teams that span multiple scientific disciplines and advance their projects not only in the lab but also by contributing to patent applications, Investigational New Drug (IND) applications, and writing manuscripts, thus working and communicating across professions. Fellows are trained in the procedures for rigor and reproducibility outlined in the Assay Guidance Manual, which increases the likelihood of accelerating observations through the translational pathway. As communication is also an integral characteristic of a translational scientist, each fellow at DPI is required to present his or her research, either orally during a monthly fellows meeting or in poster sessions. Not only does this improve their communication skills, but it also deepens their understanding of their own research. Following the framework provided by Translation Together, the DPI training office has begun to enhance the training program to have more alignment with frameworks for developing highly skilled translational scientists.

As DPI continues to grow as a translational science training program, alumni-tracking efforts will also be bolstered. For future studies, DPI is developing an alumni survey to be used in collecting self-reported data from our alumni. This survey will not only improve the availability of demographic data but will 
also assess the impact of the DPI translational science training program on the career decisions of alumni. DPI is also developing and implementing entrance and exit surveys and interviews, with an interest in determining the career goals of fellows as they enter into and transition out of DPI in order to inform the impact of the training on career goals. Though recent exit interviews suggest alumni feel their training prepared them for their next academic and career steps, a more standardized approach for collecting this information will strengthen the career outcome data reported in the future. The Coalition for Next Generation Life Science has reported that transparent reporting of training program outcomes may better inform fellows of their career options and inform training programs of areas for improvement (Blank et al., 2017). Thus, the collection of self-reported data through these methods will be essential in shaping the translational science workforce and translational science training programs.

Overall, this report shows that fellows acquiring the translational science skill set through training programs such as the one being developed at DPI are benefiting from their training and are well prepared to enter the scientific workforce.

\section{ACKNOWLEDGMENTS}

We thank Adam Yasgar and Drs. Matt Hall, Marcus Hodges, Ann Knebel, and Anton Simeonov for taking the time to critically read the paper and provide important feedback. We also thank the DPI team leads for maintaining detailed records of who has trained in their groups and providing us with this information and for their continued support of current DPI fellows and alumni. This research was supported in part by the Intramural/ Extramural research program of the NCATS, NIH.

\section{REFERENCES}

Austin, C. P. (2018). Translating translation. Nature Reviews Drug Discovery, 17(7), 455-456. doi: 10.1038/nrd.2018.27

Austin, C. P., Colvis, C. M., \& Southall, N. T. (2019). Deconstructing the translational Tower of Babel. Clinical and Translational Science, 12(2), 85. doi 10.1111/cts.12595

Bi, M., Zhao, Z., Yang, J., \& Wang, Y. (2019). Comparison of case-based learning and traditional method in teaching postgraduate students of medical oncology. Medical Teacher, 41(10), 1124-1128. doi: 10.1080/0142159X 2019.1617414

Blank, R., Daniels, R. J., Gilliland, G., Gutmann, A., Hawgood, S., Hrabowski, F. A., ... \& Schlissel, M. S. (2017). A new data effort to inform career choices in biomedicine. Science, 358(6369), 1388-1389. doi: 10.1126/science. aar4638

Bonney, K. M. (2015). Case study teaching method improves student performance and perceptions of learning gains. Journal of Microbiology $\&$ Biology Education, 16(1), 21-28. doi: 10.1128/jmbe.v16i1.846

Collins, F. S. (2011). Reengineering translational science: The time is right. Science Translational Medicine, 3(90), 90cm17. doi: 10.1126/scitranslmed 3002747

Coussens, N. P., Sittampalam, G. S., Guha, R., Brimacombe, K., Grossman, A., Chung, T. D. Y., ... \& Austin, C. P. (2018). Assay Guidance Manual: Quantitative biology and pharmacology in preclinical drug discovery. Clinical and Translational Science, 11(5), 461-470. doi: 10.1111/cts.12570

Evans, T. M., Lundsteen, N., \& Vanderford, N. L. (2017). ReSearch: A career guide for scientists. London: Academic Press.

Gibbs, K. D., Jr, McGready, J., \& Griffin, K. (2015). Career development among American biomedical postdocs. CBE-Life Sciences Education, 14(4), ar44. doi: 10.1187/cbe.15-03-0075

Gilliland, Sittampalam, G. S., Wang, P. Y., \& Ryan, P. E. (2017). The translational science training program at $\mathrm{NIH}$ : Introducing early career researchers to the science and operation of translation of basic research to medical interventions. Biochemistry and Molecular Biology Education, 45(1), 1324. doi: $10.1002 /$ bmb.20978

Gilliland, White, J., Gee, B., Kreeftmeijer-Vegter, R., Bietrix, F., Ussi, A. E., ... \& Austin, C. P. (2019). The fundamental characteristics of a translational scientist. ACS Pharmacology \& Translational Science, 2(3), 213-216. doi: 10.1021/acsptsci.9b00022

Gilliland, Zuk, D., Kocis, P., Johnson, M., Hay, S., Hajduch, M., ... \& Ussi, A. E. (2016). Putting translational science on to a global stage. Nature Reviews Drug Discovery, 15(4), 217-218. doi: 10.1038/nrd.2016.33

Hall, A., Mann, J., \& Bender, B. (2015). Analysis of scholar outcomes for the NIGMS postbaccalaureate research education program. Bethesda, MD: National Institute of General Medical Sciences.

Hall, J. D., Harrell, J. R., Cohen, K. W., Miller, V. L., Phelps, P. V., \& Cook, J. G. (2016). Preparing postbaccalaureates for entry and success in biomedical PhD programs. CBE-Life Sciences Education, 15(3), ar27. doi: 10.1187/ cbe.16-01-0054

Her, S., Jacob, M., Wang, S., Xu, S., \& Sealey, D. (2018). Non-academic employability of life science PhDs: The importance of training beyond the bench. bioRxiv, https://doi.org/10.1101/485268

Hernandez, P. R., Hopkins, P. D., Masters, K., Holland, L., Mei, B. M., Richards-Babb, M., ... \& Shook, N. J. (2018). Student integration into STEM careers and culture: A longitudinal examination of summer faculty mentors and project ownership. CBE-Life Sciences Education, 17(3), ar50. doi: $10.1187 /$ cbe.18-02-0022

Lenzi, R. N., Korn, S. J., Wallace, M., Desmond, N. L., \& Labosky, P. A. (2020) The NIH "BEST" programs: Institutional programs, the program evaluation, and early data. FASEB Journal, 34(3), 3570-3582. doi: 10.1096/ fj.201902064

Lopatto, D. (2007). Undergraduate research experiences support science career decisions and active learning. CBE-Life Sciences Education, 6(4), 297-306. doi: 10.1187/cbe.07-06-0039

Mathur, A., Brandt, P., Chalkley, R., Daniel, L., Labosky, P., Stayart, C., \& Meyers F. (2018a). Evolution of a functional taxonomy of career pathways for biomedical trainees. Journal Clinical and Translational Science, 2(2), 6365. doi: $10.1017 /$ cts.2018.22

Mathur, A., Cano, A., Kohl, M., Muthunayake, N. S., Vaidyanathan, P., Wood, M E., \& Ziyad, M. (2018b). Visualization of gender, race, citizenship and academic performance in association with career outcomes of 15-year biomedical doctoral alumni at a public research university. PLoS One, 13(5), e0197473. doi: 10.1371/journal.pone.0197473

Meyers, F. J., Mathur, A., Fuhrmann, C. N., O’Brien, T. C., Wefes, I., Labosky, P. A., ... \& Chalkley, R. (2016). The origin and implementation of the Broadening Experiences in Scientific Training programs: An NIH common fund initiative. FASEB Journal, 30(2), 507-514. doi: 10.1096/fj.15-276139

National Academies of Sciences, Engineering, and Medicine. (2018). Graduate STEM education for the 21st century. Washington, DC: National Academies Press.

National Science Foundation. (2017). Survey of doctorate recipients. https:// ncsesdata.nsf.gov/doctoratework/2017/

Pickett, C. L., Corb, B. W., Matthews, C. R., Sundquist, W. I., \& Berg, J. M. (2015). Toward a sustainable biomedical research enterprise: Finding consensus and implementing recommendations. Proceedings of the National Academy of Sciences USA, 112(35), 10832-10836. doi: 10.1073/ pnas.1509901112

Pickett, C. L., \& Tilghman, S. (2018). Becoming more transparent: Collecting and presenting data on biomedical Ph.D. alumni. PeerJ Preprints, 6, e3370v2. doi: hTtps://doi.org/10.7287/peerj.preprints.3370v2

Remich, R., Naffziger-Hirsch, M. E., Gazley, J. L., \& McGee, R. (2016). Scientific growth and identity development during a postbaccalaureate program: Results from a multisite qualitative study. CBE-Life Sciences Education, 15(3), ar25. doi: 10.1187/cbe.16-01-0035

Russell, S. H., Hancock, M. P., \& McCullough, J. (2007). The pipeline. Benefits of undergraduate research experiences. Science, 316(5824), 548-549. doi: $10.1126 /$ science.1140384

Silva, E. A., Des Jarlais, C., Lindstaedt, B., Rotman, E., \& Watkins, E. S. (2016) Tracking career outcomes for postdoctoral scholars: A call to action. PLoS Biology, 14(5), e1002458. doi: 10.1371/journal.pbio.1002458 
Sinche, M. (2016). Next gen PhD: A guide to career paths in science. Cambridge, MA: Harvard University Press.

Sinche, M., Layton, R. L., Brandt, P. D., O'Connell, A. B., Hall, J. D., Freeman A. M., ... \& Brennwald, P. J. (2017). An evidence-based evaluation of transferrable skills and job satisfaction for science PhDs. PLoS One, 12(9), e0185023. doi: 10.1371/journal.pone.0185023

Sorkness, C. A., Pfund, C., Ofili, E. O., Okuyemi, K. S., Vishwanatha, J. K., team, N., .. \& Womack, V. (2017). A new approach to mentoring for research careers: The National Research Mentoring Network BMC Proceedings, 11(Suppl 12), 22. doi: 10.1186/s12919-017 $-0083-8$

Stayart, C. A., Brandt, P. D., Brown, A. M., Dahl, T., Layton, R. L., Petrie, K. A., \& Monsalve, G. C. (2020). Applying inter-rater reliability to improve consistency in classifying PhD career outcomes. F1000Res, 9, 8. doi: 10.12688/f1000research.21046.2

St Clair, R., Hutto, T., MacBeth, C., Newstetter, W., McCarty, N. A., \& Melkers J. (2017). The "new normal": Adapting doctoral trainee career preparation for broad career paths in science. PLOS ONE, 12(5), e0177035. doi: 10.1371/journal.pone.0177035

Tsevat, J., \& Smyth, S. S. (2020). Training the translational workforce: Expanding beyond translational research to include translational science.
Journal of Clinical and Translational Science, 4, 360-362. doi: 10.1017/ cts.2020.31

Vanderford, N. L., Evans, T. M., Weiss, L. T., Bira, L., \& Beltran-Gastelum, J. (2018a). A cross-sectional study of the use and effectiveness of the individual development plan among doctoral students. F1000Res, 7, 722. doi: 10.12688/f1000research.15154.2

Vanderford, N. L., Evans, T. M., Weiss, L. T., Bira, L., \& Beltran-Gastelum, J. (2018b). Use and effectiveness of the individual development plan among postdoctoral researchers: Findings from a cross-sectional study. F1000Res, 7, 1132. doi: 10.12688/f1000research.15610.2

Weggemans, M. M., van der Schaaf, M., Kluijtmans, M., Hafler, J. P., Rosenblum, N. D., \& Prakken, B. J. (2018). Preventing translational scientists from extinction: The long-term impact of a personalized training program in translational medicine on the careers of translational scientists. Frontiers in Medicine, 5, 298. doi: 10.3389/fmed.2018.00298

Xu, H., Gilliam, R. S. T., Peddada, S. D., Buchold, G. M., \& Collins, T. R. L. (2018) Visualizing detailed postdoctoral employment trends using a new career outcome taxonomy. Nature Biotechnology, 36(2), 197-202. doi: 10.1038/nbt.4059

Zimmerman, A. M. (2018). Navigating the path to a biomedical science career. PLoS One, 13(9), e0203783. doi: 10.1371/journal.pone.0203783 